\title{
Editorial: Advances in Health-Care Transition for Patients With Childhood-Onset Chronic Diseases: International Perspectives
}

\author{
Yuko Ishizaki ${ }^{1 *}$, Mitsue Maru² and Hirohiko Higashino ${ }^{3}$ \\ ${ }^{1}$ Department of Pediatrics, Kansai Medical University, Moriguchi, Japan, ${ }^{2}$ International Nursing Development, School of \\ Nursing and Rehabilitation, Konan Women's University, Kobe, Japan, ${ }^{3}$ Higashino Clinic, Higashi-Osaka, Japan
}

Keywords: health-care transition, childhood-onset chronic diseases, pediatrics, adolescent, childhood-cancer, psychology, Turner syndrome

Editorial on the Research Topic

Advances in Health-Care Transition for Patients With Childhood-Onset Chronic Diseases: International Perspectives

For adult patients with childhood-onset chronic diseases (APCCD), the transition from child- to adult-centered health care is an important topic in both medical practice and economics worldwide. Advances in pediatrics and neonatal medicine have dramatically improved the prognosis for children with previously fatal chronic diseases, allowing them to survive into adulthood (1-3).

OPEN ACCESS

Edited by:

Joav Merrick,

Ministry of Social Affairs, Israel

Reviewed by:

Mohammed Morad

Clalit Health Services, Israel

*Correspondence:

Yuko Ishizak

ishizaky@takii.kmu.ac.jp

Specialty section: This article was submitted to Child Health and Human Development, a section of the journal

Frontiers in Pediatrics

Received: 01 March 2018 Accepted: 15 March 2018 Published: 29 March 2018

Citation: Ishizaki Y, Maru M and Higashino H (2018) Editorial: Advances in Health-Care Transition for Patients

With Childhood-Onset Chronic Diseases: International Perspectives.

Front. Pediatr. 6:80.

doi: 10.3389/fped.2018.00080
The number of adolescents undergoing health-care transition is increasing (2-10); therefore, suitable programs are required to integrate the patients into adult-centered care and to help them grow socially and become independent, working adults.

This transition has been defined as a multifaceted, active process that attends to the medical, psychosocial, and educational needs of adolescents as they move from child- to adult-centered care (4). Transition programs should involve patients, families, pediatricians, nurses, adult healthcare providers, and other health-care professionals $(11,12)$, and they should encompass medical, psychosocial, and ethical issues adequate to the various cultural and religious backgrounds.

By presenting a new movement of transition in Asia, Ishizaki et al., integrated the most recent advances in Japan. In terms of APCCD health-care transition history, Japan falls behind the American and European countries. The term "transition program" was introduced in 2006 in the clinical context, and the concept of health-care transition rapidly spread over the last 10 years due to the measures taken by the Japan Pediatric Society and Ministry of Health, Labor, and Welfare.

Various articles from several countries were published, which focused on the health-care transition of patients of childhood cancer. Magni et al. reported their trials named "The Youth Project" in Milano, which supported adults and adolescents (AYA) with pediatric cancer. The project contained not only medical procedures but also creative activities such as fashion collections, song writing, novel writin g, a photography course, and exhibitions and other support activities such as sports.

Using a focus group methodology, Aldiss et al. investigated the views of the professionals involved in transitional care in London, gathering information on the process of transition and its barriers and facilitators. They found eight key factors that impact transition.

Raz et al. evaluated the effect of providing information on the quality of life or mental pain at the time of diagnosis and found that there were differences between younger patients with childhood cancer and the older adults, when they received the diagnosis with or without information about their cancer.

Cancer pain consists of both somatic components and psychosocial elements, affecting the children's psychosocial development. Scarponi and Pession expressed their opinion about implementing 
group psychotherapy as a means to get over the pain caused by childhood cancer.

Sakakibara advocated that women with Turner syndrome (TS) received inadequate health care in terms of hormone replacement therapy, to acquire secondary sexual characteristics when patients with TS are managed in only pediatrics. Gynecologists should be involved in the initiation of HRT to create a smoother transition.

These research topics present the latest information about advances in health-care transition obtained from multifaceted

\section{REFERENCES}

1. Por J, Golberg B, Lennox V, Burr P, Barrow J, Dennard L. Transition of care: health care professionals' view. J Nurs Manag (2004) 12(5):354-61. doi:10.1111/j.1365-2834.2004.00428.x

2. Kennedy A, Sloman F, Douglass JA, Sawyer SM. Young people with chronic illness: the approach to transition. Intern Med J (2007) 37(8):555-60. doi:10.1111/j.1445-5994.2007.01440.x

3. Riley K, Roth S, Sellwood M, Wyatt JS. Survival and neurodevelopmental morbidity at 1 year of age following extremely preterm delivery over a 20-year period: a single centre cohort study. Acta Paediatr (2008) 97(2):159-65. doi:10.1111/j.1651-2227.2007.00637.x

4. Blum RW, Garell D, Hodgman CH, Jorissen TW, Okinow NA, Orr DP, et al. Transition from child-centered to adult health-care systems for adolescents with chronic conditions. A position paper of the Society for Adolescent Medicine. J Adolesc Health (1993) 14(7):570-6. doi:10.1016/1054-139X(93)90143-D

5. Schidlow DV, Fiel SB. Life beyond pediatrics. Transition of chronically ill adolescents from pediatric to adult health care systems. Med Clin North Am (1990) 74(5):1113-20. doi:10.1016/S0025-7125(16)30505-3

6. Rosen DS. Between two world: bridging the cultures of child health and adult medicine. J Adolesc Health (1995) 17(1):10-6. doi:10.1016/1054-139X (95)00077-6

7. Scal P, Evans T, Blozis S, Okinow N, Blum R. Trends in transition from pediatric to adult health care services for young adults with chronic conditions. J Adolesc Health (1999) 24(4):259-64. doi:10.1016/S1054-139X(98) 00127-X

8. American Academy of Pediatrics, American Academy of Family Physicians, American College of Physicians-American Society of Internal Medicine. professionals. These topics provide useful information for the next steps in promoting health-care transition worldwide.

\section{AUTHOR CONTRIBUTIONS}

All authors participated in the design of this Research Topic. YI and MM recommended contributors. HH have made an intellectual contribution to the work. All authors approved it for publication.

A consensus statement on health care transitions for young adults with special health care needs. Pediatrics (2002) 110(6 Pt 2):1304-6.

9. Reiss JG, Gibson RW, Walker LR. Health care transition: youth, family and provider perspectives. Pediatrics (2005) 115(1):112-20. doi:10.1542/peds. 2004-1321

10. American Academy of Pediatrics, American Academy of Family Physicians, American College of Physicians, Transitions Clinical Report Authoring Group, Cooley WC, Sagerman PJ. Supporting the health care transition from adolescence to adulthood in the medical home. Pediatrics (2011) 128(1):182-200. doi:10.1542/peds.2011-0969

11. Bronheim S, Fiel S, Schidlow D, MaGrab P, Boczar K, Dillon C. Crossing: A Manual for Transition of Chronically Ill Youth to Adult Health Care. Available from: https://www.researchgate.net/publication/265108158_Crossings_a_ manual_for_transition_of_chronically_ill_youth_to_adult_health_care

12. McDonagh JE, Kelly DA. Transitioning care of the pediatric recipient to adult caregivers. Pediatr Clin N Am (2003) 50(6):1561-83. doi:10.1016/ S0031-3955(03)00131-7

Conflict of Interest Statement: The authors declare that the research was conducted in the absence of any commercial or financial relationships that could be construed as a potential conflict of interest.

Copyright (c) 2018 Ishizaki, Maru and Higashino. This is an open-access article distributed under the terms of the Creative Commons Attribution License (CC BY). The use, distribution or reproduction in other forums is permitted, provided the original author(s) and the copyright owner are credited and that the original publication in this journal is cited, in accordance with accepted academic practice. No use, distribution or reproduction is permitted which does not comply with these terms. 